\title{
A Review on - Performance Evaluation of Routing Protocols in MANETs using ACO
}

\author{
Anubha \\ Research Scholar \\ IKG PTU, Kapurthala \\ Punjab, India
}

\begin{abstract}
The emerging capabilities of mobile devices have given a new direction to the internet, which decreases the cost and allow us to use infrastructure wireless networks and infrastructure less wireless networks (i.e. Mobile Ad Hoc Wireless Network). Mobile ad-hoc network (MANET) is one of the most encouraging fields of research and development of wireless network. Sending information across the network from a source to a destination is one of the major issues in communication network. In a mobile ad hoc network, the complexity increases due to various characteristics like dynamic topology, absence of centralized authority, time varying QoS Requirements etc. To overcome this problem a number of routing protocols have been developed. It is not easy to determine which protocols may perform well under a number of different network scenarios such as network size and topology etc. In this paper we provide an overview of a wide range of the existing routing protocols with a particular focus on their characteristics and functionality using Ant Colony Optimization (ACO) technique for developing routing algorithms for ad hoc networks.
\end{abstract}

\section{Keywords}

ACO, MANET, OLSR, AODV, DSR, TORA, Routing Protocol, QoS

\section{INTRODUCTION}

Mobile Ad-hoc Network (MANET) is a decentralized independent wireless system which consists of free nodes and a self-organizing capability and due to its demanding application, its bit complex to find route between nodes. In this review, paper presents comparison of different routing parameters of proactive and reactive routing in order to evaluate the better routing technique. And evaluate performance of algorithm for their better improvement and using secure mechanism for transmitting data in MANET.

Wireless networks provide connection flexibility between users in different places. Moreover, the network can be extended to any place or building without the need for a wired connection. Wireless networks are divided into two categories:

Infrastructure networks: An Access Point (AP) acts a central coordinator for all nodes. Any node can be joining the network through AP. Also, AP organizes the connection between the Basic Set Services (BSSs) so that the route is ready when it is needed. However, one disadvantage of using an infrastructure network is the big overhead of maintaining the routing tables. [8]

Ad Hoc networks: The network is ad hoc because it does not rely on an already defined infrastructure, such as routers in wired networks or access points in wireless networks. Ad Hoc networks do not have a centralised control point. Thus, sending and receiving packets are more vapid than the fixed infrastructure networks. In mobile ad hoc network (MANET), the nodes work together in a distributed fashion without any centralized administration. Each node can act as a receiver, transmitter or router. The nodes instantaneously and dynamically form a network on the fly when they are needed. Because of the lack of centralized control, routing becomes a central issue and a major challenge as the network topology is constantly changing. MANET requires efficient routing algorithm in order to reduce the amount of signalling introduced due to maintaining valid routes, and consequently enhance the overall performance of the MANET system. A MANET routing algorithm should not only be capable of finding the shortest path between the source and destination, but it should also be adaptive, in terms of the changing state of the nodes, the changing load conditions of the network and the changing state of the environment .[8]
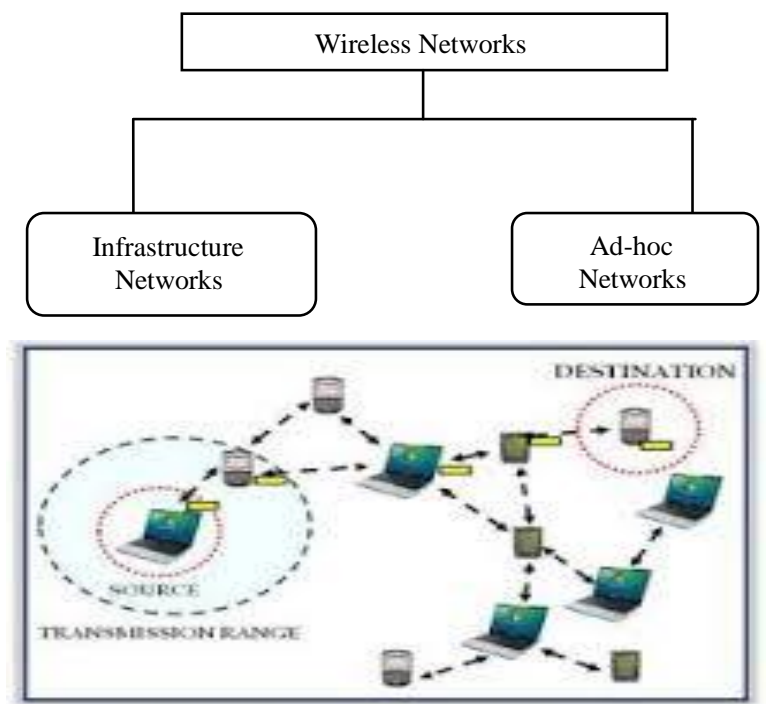

Figure 1: No Infrastructure (ad hoc networks): no base stations; no fixed network infrastructure [25]

\section{RELATED WORK}

2.1 Analysis of Ant Colony Optimization Based Protocols in MANETs by Tasbir Singh and Jaswinder Singh (2014) In this paper a new ACO based protocol SARA has been proposed and implemented. It is a new technique to reduce the overhead based on the concept of Control Neighbor Broadcast $(\mathrm{CNB})$. This algorithm overcomes the limitations of ACO hence used to solve routing problems in highly dynamic mobile ad hoc networks. Finally, the result of SARA has been compared with the AntHocNet protocol on the four parameters average energy, throughput, delay and overhead. The result shows that the SARA protocol has more throughput and average energy and small overhead and delay as compared to AntHocNet protocol. 
2.2 A Study of Efficient Anonymous Routing Protocols in MANET by Anupriya Augustine, Jubin Sebastian E (2014)

This paper provides an overview of most efficient anonymous routing protocols in MANET and examines the security efficiency of these protocols. The parameters consider for the comparative study of these protocols are the number of actual participating nodes in the network, latency in packet transmission, packet delivery rate and the transmission cost. The protocols taken in to account include, AO2P, ALARM and ALERT.

2.3 Comparative Analysis of AntHocNet, AODV, DSR Routing Protocols for Improvising Loss Packet Delivery Factor by Maahi Amit Khemchandani\#1, Prof. B. W. Balkhande (2014)

This paper simulates and analysis the dynamic performance of AntHocNet routing protocol with IEEE 802.11 MAC protocol in random way point model using NS2. Performance of AntHocNet is compared with two reference routing algorithm like Adhoc Online Distance Vector (AODV) and Dynamic Source Routing (DSR) algorithm and the results have been analyzed based on lost packet ratio and normalized routing overhead by varying number of nodes, for different pause time and for different speed.

2.4 Energy Efficient Routing in Wireless Sensor Networks based on Ant Colony Optimization byOkafor, Friday Onyema and Fagbohunmi, Griffin Siji (2013)

This paper suggests a heuristic way to reduce energy consumption in WSNs routing process using Ant Colony Optimization. The paper explains that wireless sensor networks (WSN's) have become an important and challenging research area in recent years and the nodes bearing limited power in Wireless Sensor Networks are deployed to gather useful information from the field. Since in WSNs it is critical to collect the information efficiently, swarm intelligence based optimization technique known as Ant Colony Optimization has been utilized in network routing. In this paper, three Ant Colony Optimization algorithms, the Ant System, Ant Colony System and improved Ant System and their application in WSN routing process are proposed. The simulation results show that Ant Colony Optimization is an effective way to reduce energy consumption and maximize WSN lifetime.

2.5 MANET routing protocols based on swarm intelligence by Iliya Enchev Pervasive and Artificial Intelligence Research Group (2011)

A number of state of the art swarm-intelligence inspired MANET protocols are considered in this work and put to partial comparison. It is shown that by using ideas taken from the simple behavior of ants and bees optimization and innovations in routing protocols can be done, that help outperform the standard MANET routing protocols like AODV, DSDV, DSR.

2.6 Ant Colony based Routing for Mobile Ad-Hoc Networks towards Improved Quality of Services by Bibhash Roy, SumanBanik, ParthiDey, SugataSanyal, NabenduChak

In this paper, a new QoS algorithm for mobile ad hoc network has been proposed. The proposed algorithm combines the idea of Ant Colony Optimization (ACO) with Optimized Link State Routing (OLSR) protocol to identify multiple stable paths between source and destination nodes. One of the major issues in MANET is routing due to the mobility of the nodes. When it comes to MANET, the complexity increases due to various characteristics like dynamic topology, time varying QoS requirements, limited resources and energy etc. QoS routing plays an important role for providing QoS in wireless ad hoc networks. The biggest challenge in this kind of networks is to find a path between the communication end points satisfying user's QoS requirement. Nature-inspired algorithms (swarm intelligence) such as ant colony optimization (ACO) algorithms have shown to be a good technique for developing routing algorithms for MANETs.

2.7 A Study of MANET Routing Protocols: Joint Node Density, Packet Length and Mobility by Nurul I. Sarkar and Wilford G. Lol (2010)

This paper investigates the combined effect of node density, packet length and mobility for four routing protocols (OLSR, AODV, DSR, and TORA) on an 802.11 MANET. In this paper, OPNET-based simulation models has been developed to study the performance of OLSR, AODV, DSR, and TORA for small, medium and large (dense) network scenarios with varying packet length and node mobility. Simulation results obtained show that node density and mobility has a significant impact on underlying routing protocols.

\section{ANT COLONY OPTIMIZATION}

The ant colony optimization is brainwave from real ants which are roving around their nests to forage for search of food. Ant as an individual has a limited efficacy. But a part of well-organised colony, it becomes one powerful agent, working for the development of the colony. A colony of ants has a wide range of duties like collecting food, building/guarding the nest, removing the dead ants, etc. and has simple one-to-one communication. Ants use a chemical substance pheromone for communication among them which they deposit on the ground while roaming around for search of food. Ants have ability to smell this pheromone. They can produce few different types of pheromones - usually one each to signify different work categories like collecting food trails, signifying emergency, moving dead ants, etc. The source of ACO is the pheromone trail laying and following behaviour of ants which use pheromone as a communication medium.

There are chances that when ants fan out to find food, any ant finds a short path to a new food source. It then takes some food with it and makes its way back to the nest. Since it is attracted by its own pheromone trail, it is likely that the ant follows its own path back to the nest, thereby leaving a second pheromone trail. If other ants happened to take a longer path to the food source, they arrive after the first ant and, when trying to make their way back to the nest, there is a good chance for them to be attracted by the short path, where already two pheromone trails have been laid. This reinforces the short path even more and makes it more attractive. Concerning the longer path, pheromones tend to evaporate after some time, so in the long run the long paths will be forgotten and almost all ants will take the short path. The characteristics of ants are similar to the characteristics of MANETs. This helps us to apply the food searching characteristics of ants for routing packets in MANETs. [7]

ACO helps in communication network to find shortest route with help of two phases namely path discovery phase and path maintenance phase. When a source node has to pass data to a destination node, it starts with the path discovery phase. Once the path is found, the data transfer will take place. While data transmission is going on, it is also required to maintain the path to the destination. This is very much desirable and required in mobile ad hoc networks. 


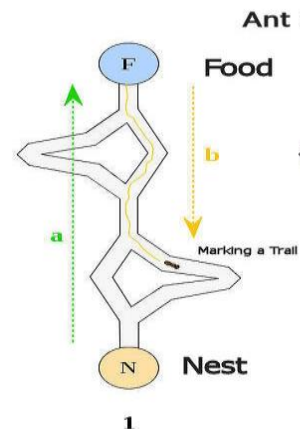

Ant Colony Optimization

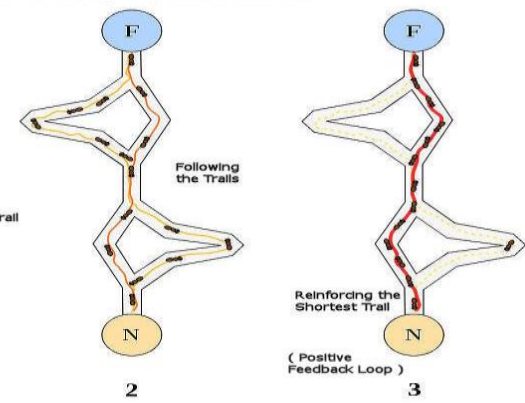

Figure 2: shows behaviour of Ant Searching for food [9].

a) Path Discovery Phase: include following steps:

1. Let the source node $S$ has data to send to a destination $D$ with Quality of Services requirements maximum transmission rate, minimum delay and more bandwidth. A list of nodes that are more and more visited by the ant is called visited nodes list. This list forms the route $\mathrm{R}$ from the source node to destination node.

2. Initially choose the source node $\mathrm{S}$.

3. S initiates a Path_Request_Ant to destination $D$ through all its neighbours which are in 1-hop distance from S. The Path_Request_Ant contains source address, destination address, hop count and bandwidth.

4. After that the pheromone evaporation of all the 1- hop distance nodes will be calculated. Each node (i) maintains a table ; a table of Pheromones specifying the quantity of available pheromone on each link $(\mathrm{V} i, \mathrm{~V} j)$. This quantity is initialized to constant $\mathrm{C}$. Then we calculate the pheromone evaporation of all the 2-hop distance nodes.

5. At last we calculate the probability value of each path from source $S$ with the help of pheromone evaporation of every node.

6. If calculated path preference probability value is best than the requirements, the path is accepted and stored in memory. Data transmission can be started along that path.

7. When the Path_Request_Ant reaches the destination, it will be converted as Path_Reply_Ant and forwarded towards the original source. The Path_Reply_Ant will take the same path of the corresponding Path_Request_Ant but in reverse direction [5].

\section{b) Path Maintenance Phase}

The second phase of the routing algorithm is route maintenance, no special packets for route maintenance is required. Once the Forward Ant and Backward Ant have established the pheromone tracks for the source and destination nodes, subsequent data packets are used to maintain the path. Similar to the nature, established paths do not keep their initial pheromone values forever. When a node (relay node) relays a data packet toward the destination (destination address) to a neighbour node (next hop), it increases the pheromone value of the entry (destination address, next hop, pheromone value) by pheromone function, i.e., the path to the destination is strengthened by the data packets. In contrast, the next hop (next hop) increases the pheromone value of the entry (source address, relay node, pheromone value) by pheromone function, i.e. the path to the source node is also strengthened. Nodes can recognize duplicate receptions of data packets, based on the source address and the sequence number. If a node receives a duplicate packet, it sets the DUPLICATE ERROR flag and sends the packet back to the previous node. The previous node deactivates the link to this node, so that data packets cannot be sending to this direction any more [5].

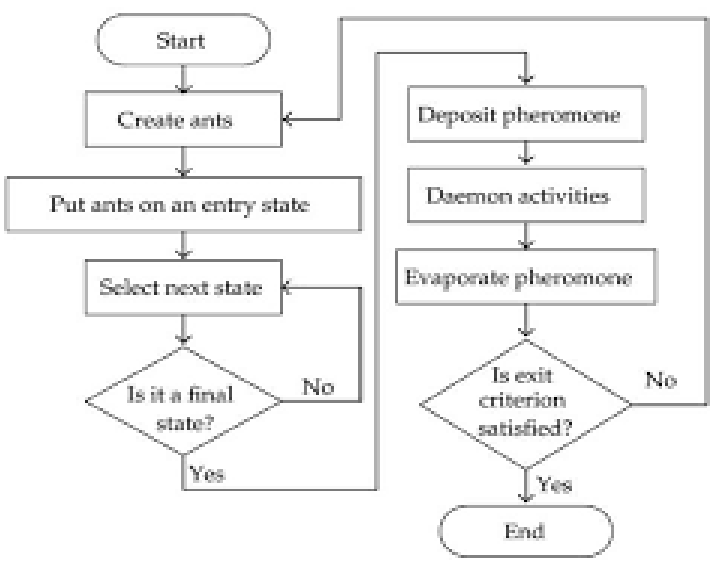

Figure 3: Flowchart of behaviour of an Ant

The Following table shows comparison between Ant and Nodes in Manets [20].

\begin{tabular}{|l|l|l|}
\hline Parameters & MANETs & Ants \\
\hline $\begin{array}{l}\text { Physical } \\
\text { structure }\end{array}$ & $\begin{array}{l}\text { Unstructured, } \\
\text { dynamic } \\
\text { \& distributed }\end{array}$ & -do- \\
\hline $\begin{array}{l}\text { Basic } \\
\text { system }\end{array}$ & $\begin{array}{l}\text { Self-configuring } \\
\text { \&self organizing }\end{array}$ & -do- \\
\hline Motive & $\begin{array}{l}\text { To find the shortest } \\
\text { path }\end{array}$ & $\begin{array}{l}\text { Guaranteed } \\
\text { shortest path }\end{array}$ \\
\hline Overhead & More & Less \\
\hline $\begin{array}{l}\text { Packet Delivery } \\
\text { Ratio }\end{array}$ & Less & More \\
\hline $\begin{array}{l}\text { Route Discovery } \\
\text { Procedure }\end{array}$ & $\begin{array}{l}\text { Route Request/Reply } \\
\text { message are used }\end{array}$ & $\begin{array}{l}\text { Pheromone } \\
\text { value is used }\end{array}$ \\
\hline Path Discovered & $\begin{array}{l}\text { Single path, partially } \\
\text { multipath }\end{array}$ & Multipath \\
\hline
\end{tabular}

\section{ROUTING PROTOCOLS}

\subsection{Proactive Routing Protocol}

In this Proactive Routing Protocol, each and every node in the network maintains routing information to every other node in the network. Routes information is generally kept in the routing tables and is periodically updated as the network topology changes. . Current routing protocol like Link State Routing (LSR) protocol (open shortest path first) and the Distance Vector Routing Protocol (Bellman-Ford algorithm) are not suitable to be used in mobile environment. Destination Sequenced Distance Vector Routing protocol (DSDV) and Wireless routing protocols were proposed to eliminate counting to infinity and looping problems of the distributed Bellman-Ford Algorithm. The proactive protocols are not suitable for larger networks, as they need to maintain node entries for each and every node in the routing table of every node. This causes more overhead in the routing table leading to consumption of more bandwidth. Examples of Proactive Routing Protocols are: a) Global State Routing (GSR). b) Hierarchical State Routing (HSR). c) Destination Sequenced Distance Vector Routing (DSDV). [4] 
Advantages

- $\quad$ Routing information already present, reduce latency in the network.

- High storage capacity due to the routing tables.

\section{Disadvantages}

- Not suitable for large networks.

- Cost of maintaining the network is high, if network topology changes frequently. [3]

\subsection{Reactive Routing Protocol}

Reactive is also called On Demand routing protocol. Reactive protocols since they don't maintain routing information or routing activity at the network nodes when there is no communication. If a node wants to send a packet to another node then this protocol searches for the route in an on-demand manner and establishes the connection in order to transmit and receive the packet. A route search is needed for every new destination therefore the communication overhead expense is reduced. The route discovery usually occurs by flooding the route request packets throughout the network. [16] Examples of reactive protocols are: a) Ad hoc Ondemand Distance Vector Routing (AODV). b) Dynamic Source Routing (DSR). c) Location Aided Routing (LAR). d) Temporally Ordered Routing Algorithm (TORA).

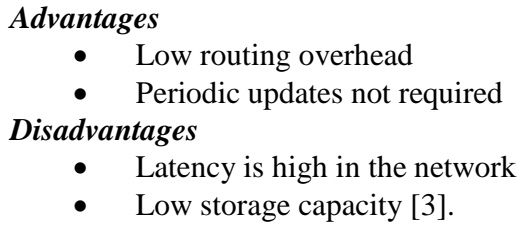

\begin{tabular}{|l|l|l|}
\hline Parameters & Reactive & Proactive \\
\hline $\begin{array}{l}\text { Availability } \\
\text { of routing } \\
\text { Information }\end{array}$ & $\begin{array}{l}\text { After a route } \\
\text { discovery }\end{array}$ & $\begin{array}{l}\text { Immediately } \\
\text { from route table }\end{array}$ \\
\hline $\begin{array}{l}\text { Route } \\
\text { Updates }\end{array}$ & When requested & $\begin{array}{l}\text { Periodic } \\
\text { Advertisements }\end{array}$ \\
\hline $\begin{array}{l}\text { Average End- } \\
\text { to-End Delay }\end{array}$ & Variable & Constant \\
\hline Efficiency & More & Less \\
\hline Performance & Faster & Less \\
\hline $\begin{array}{l}\text { Adaptive } \\
\text { Nature }\end{array}$ & $\begin{array}{l}\text { More Adaptive and } \\
\text { work much better in } \\
\text { different topographies. }\end{array}$ & Less \\
\hline
\end{tabular}

\subsection{Comparison between Reactive and Proactive}

Below Table shows comparison between Proactive and Reactive Protocol [15].

\subsection{Comparison of Reactive Protocols}

Below Table shows comparison between different protocols in Reactive Routing [13-14].

\begin{tabular}{|l|l|l|l|}
\hline Properties & AODV & DSR & TORA \\
\hline Route Creation & $\begin{array}{l}\text { Through } \\
\text { source }\end{array}$ & $\begin{array}{l}\text { Through } \\
\text { source }\end{array}$ & Locally \\
\hline Periodic updating & No & No & NO \\
\hline $\begin{array}{l}\text { Performance } \\
\text { Metrics }\end{array}$ & Speed & Smallness & Speed \\
\hline Routing overhead & High & High & High \\
\hline
\end{tabular}

\begin{tabular}{|l|l|l|l|}
\hline $\begin{array}{l}\text { Caching } \\
\text { overhead }\end{array}$ & Low & High & Medium \\
\hline Throughput & High & Low & Low \\
\hline Route updating & $\begin{array}{l}\text { Non- } \\
\text { periodic }\end{array}$ & $\begin{array}{l}\text { Non- } \\
\text { periodic }\end{array}$ & $\begin{array}{l}\text { High } \\
\text { routing } \\
\text { overhead }\end{array}$ \\
\hline Multiple routes & No & Yes & Yes \\
\hline $\begin{array}{l}\text { Requires reliable } \\
\text { or Sequenced } \\
\text { data No }\end{array}$ & No & Yes \\
\hline
\end{tabular}

\section{PERFORMANCE MEASURES}

If only two nodes want to communicate with each other and are situated very closely to each other, then no specific Routing Protocols or Routing decisions are necessary. On the other hand, if there are a number of mobile hosts wishing to communicate beyond the limit of transmission range, then the Routing Protocols play important role in this case, some essential decisions have to be made such as which is the optimal route from the source to the destination. Thus it becomes necessary to transfer the data with the minimal delay and with maximum throughput. Various Quality of Service parameters are needed while choosing a protocol for MANET are as follows:

5.1 Throughput: The rate at which the data packet is delivered effectively from one node to another in network is known as throughput. The throughput is usually measured in bits per second (bits/sec). Throughput= (number of delivered packet *packet size)/total duration of simulation time. [21]

5.2 Average Delay: The average time it takes a data packet to reach the destination. This includes all possible delays caused by buffering during route discovery latency, queuing at the interface queue. This metric is calculated by subtracting time at which first packet was transmitted by source from time at which first data packet arrived to destination. [23] Mathematically, it can be defined as:

Average delay $=\sum$ (Time (Destination received packetTime (Send Packet))/Number of packets

5.3 Multicasting: This is the ability to send packets to multiple nodes at once. This is similar to broadcasting except the fact that the broadcasting is done to all the nodes in the network [22]. This is important as it takes less time to transfer data to multiple nodes.

5.4 Loop Free: A path taken by a packet never transits the same intermediate node twice before it arrives at the destination. This avoids waste of bandwidth or CPU consumption.

5.5 Multiple Routes If one route gets broken due to some failure, then the data could be sent through some other route. Thus, the protocol should allow creating multiple routes.

5.6 Distributed Operation: The protocol should be distributed. It should not be dependent on a centralized node.

5.7 Packet Delivery Ratio is the measure which is used to calculate how the packets are delivered based on the quality. [24] Mathematically,

$P D R=$ No. of Packets received/No. of Packets Send 


\section{CONCLUSION}

The studies done so far however show that number of protocols have been developed for ad-hoc mobile networks to achieve high throughput, end to end delay, delay jitter, packet delivery fraction and low normalize routing load and energy. The main aim is to find the optimize path to send the packets and further increase the lifetime of network. The four main factors to be considered in optimizing route between source and destination are Pheromone value, Residual energy Mobility of the nodes, Euclidean distance between node and destination.

Ant algorithms belong to a class of Meta heuristics, which have a scope of application to practical problems faced in business and industrial environments.

The various behaviours of real ants such as foraging and brooding behaviours which can provide good solutions to real time optimization problems.

The indirect communication and the cooperative interaction of the artificial ant agents, which is inspired from their real living counterpart, exhibit great flexibility and responsiveness to dynamic problems. The application of these algorithms and experimental validation of them is greatly researched owing to their capability to provide near global optimal solution to a given complex problem structure like local search, image mapping and compression, database search.

\section{REFERENCES}

[1] Krishnan Krishnaiyer, S. Hossein Cheraghi, Ant Algorithms: Review and Future Applications.

[2] R.T.Thivya lakshmi, R.Srinivasan, G.S.Raj, An Efficient Algorithm for Improving Qos in manets.

[3] Rajiv Chechi, Vikas Malik and Ompal Gupta, "Classification of Routing Protocols in MANET \& their Pros \& Cons: A Review", International Journal of Research in IT \& Management, Vol. 2, No. 11, pp. 2831, 2012.

[4] Amit Shrivastava, Aravinth Raj Shanmogavel ,Avinash Mistry, Nitin Chander, Prashanth Patlolla ,Vivek Yadlapalli Overview of Routing Protocols in MANET's and Enhancements in Reactive Protocols .

[5] Ssowjanya harishankar, Energy Aware Ant Colony Optimization Based Routing For Mobile AD HOC Networks.

[6] Osama H. Hussein, Member, IEEE, Tarek N. Saadawi, and Myung Jong Lee, Senior Member, IEEE, Probability Routing Algorithm for Mobile Ad hocnetworks' Resources Management

[7] Bibhash Roy, Suman Banik, Parthi Dey, Sugata Sanyal, Nabendu Chaki, Ant Colony based Routing for Mobile Ad-Hoc Networks towards Improved Quality of Services.

[8] Dr.S.S.Dhenakaran, A.Parvathavarthini, An Overview of Routing Protocols in Mobile Ad-Hoc Network

[9] Anirudh Shekhawat, Pratik Poddar ,Dinesh Boswal “Ant Colony Optimization Algorithms: Intoduction and Beyond"

[10] Giancarlo Pellegrino , relatore Prof. Ing. Salvato Riccobene - "Analisi basata su simulazione delle prestazioni delle reti MANET in ns2" - Progetto finale;Security in Manet

[11] Perumalsamy Deepalaksh and Shanmugasundaram Radh akrishnan, An ant colony-based multi objective quality of service routing for mobile ad hoc networks.

[12] Miss Sayali R. Parate, Jagruti Wankhad ,Review On: Improvement Of The Performance Of Mobile AD Hoc Network Using ANT COLONY OPTIMIZATION.

[13] Krishna Gorantala, Ume ${ }^{\circ}$ Routing Protocols in Mobile Ad-hoc Networks University Department of Computing Science SE-901 $87 \mathrm{UME}^{\circ}$ A SWEDEN

[14] K. Ramesh Reddy , S.Venkata Raju , N.Venkatadri Reactive, Proactive MANET Routing Protocol Comparison International Journal of Video \& Image Processing and Network Security IJVIPNS-IJENS Vol:12 No:05

[15] Shashank Awasthi , Naveen Chauhan , Arun Pratap Srivastava Performance Analysis of Proactive, Reactive and Hybrid Routing Protocol in Manet.

[16] Hrituparna Paul, Dr. Prodipto Das Performance Evaluation of MANET Routing Protocols.

[17] Manjula Poojary, B.Renuka ANT COLONY OPTIMIZATION ROUTING to MOBILE AD HOC NETWORKS in URBAN ENVIRONMENTS.

[18] Dweepna Garg \& Parth Gohil, Ant Colony Optimized Routing For Mobile Adhoc Networks (Manet).

[19] Perumalsamy Deepalakshmi and Shanmugasundaram Radhakrishnan,An ant colony-based multi objective quality of service routing for mobile $a d$ hoc networks

[20] Anuj K. Gupta, Harsh Sadawarti, and Anil K. Verma, MANET Routing Protocols Based on Ant Colony Optimization.

[21] Kiranveer Kaur ,Surinderjit Kaur, Vikramjit Singh Department of Computer Science, Punjabi University, Patiala, Throughput Analysis of Proactive and Reactive MANET Routing Protocols.

[22] Surendra H. Raut, Hemant P. Ambulgekardept. Of CSE, SGGS IE\&T, Nanded, India, Proactive and Reactive Routing Protocols in Multihop Mobile Ad hoc Network.

[23] Pankaj Rohal , Ruchika Dahiya, Prashant Dahiya, Study and Analysis of Throughput, Delay and Packet Delivery Ratio in MANET for Topology Based Routing Protocols (AODV, DSR and DSDV),International Journal For Advance Research In Engineering And Technology, Vol. 1, Issue Ii, Mar. 2013 ISSN 2320-6802

[24] Anand R, Jitendranth Mungara, Improving Quality Of The Services In Manet Usign The Hierarchical Fair Service Curve And Fisheye State Routing Protocol, International Journal of Engineering And Computer Science ISSN: 2319-7242 Volume 5 Issue 12 Dec. 2016 Page No. 19348-19353

[25] Sachi Pandey, Vibhore Tyagi, Performance Analysis of Wired and Wireless Network using NS2 Simulator, International Journal of Computer Applications (0975 8887) Volume72- No.21, June 2013 